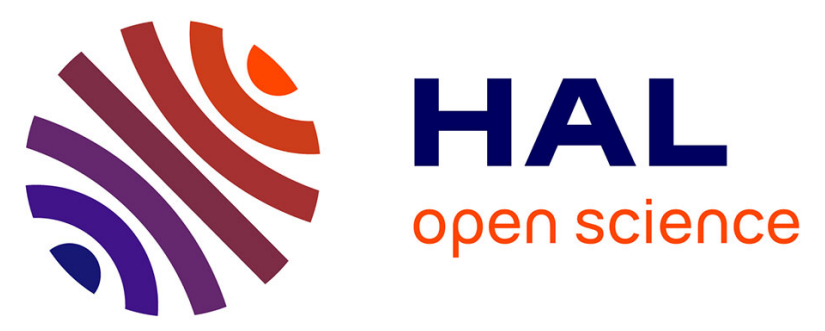

\title{
Nanometer-scale precipitations in a selective electron beam melted nickel-based superalloy
}

Shubham Chandra, Xipeng Tan, R. Lakshmi Narayan, Marion Descoins, Dominique Mangelinck, Shu Beng Tor, Erjia Liu, Gerald Seet

\section{To cite this version:}

Shubham Chandra, Xipeng Tan, R. Lakshmi Narayan, Marion Descoins, Dominique Mangelinck, et al.. Nanometer-scale precipitations in a selective electron beam melted nickel-based superalloy. Scripta Materialia, 2021, 194, pp.113661. 10.1016/j.scriptamat.2020.113661 . hal-03454753

\section{HAL Id: hal-03454753 https://hal.science/hal-03454753}

Submitted on 29 Nov 2021

HAL is a multi-disciplinary open access archive for the deposit and dissemination of scientific research documents, whether they are published or not. The documents may come from teaching and research institutions in France or abroad, or from public or private research centers.
L'archive ouverte pluridisciplinaire HAL, est destinée au dépôt et à la diffusion de documents scientifiques de niveau recherche, publiés ou non, émanant des établissements d'enseignement et de recherche français ou étrangers, des laboratoires publics ou privés.

\section{(1) (1) $\$$}

Distributed under a Creative Commons Attribution - NonCommercial - NoDerivatives| 4.0 


\title{
Nanometer-Scale Precipitations in a Selective Electron Beam Melted
} Nickel-Based Superalloy

\author{
Shubham Chandra ${ }^{\mathrm{a}}$, Xipeng Tan ${ }^{\mathrm{a}, *}$, R. Lakshmi Narayan ${ }^{\mathrm{b}}$, Marion Descoins ${ }^{\mathrm{c}}$, \\ Dominique Mangelinck $^{\mathrm{c}}$, Shu Beng Tor ${ }^{\mathrm{a}}$, Erjia Liu ${ }^{\mathrm{a}}$, Gerald Seet ${ }^{\mathrm{a}}$ \\ a Singapore Centre for 3D Printing, School of Mechanical and Aerospace Engineering, \\ Nanyang Technological University, 50 Nanyang Avenue, Singapore 639798 \\ ${ }^{\mathrm{b}}$ Department of Materials Science and Engineering, Indian Institute of Technology, Delhi, \\ Hauz Khas, New Delhi, India 110016

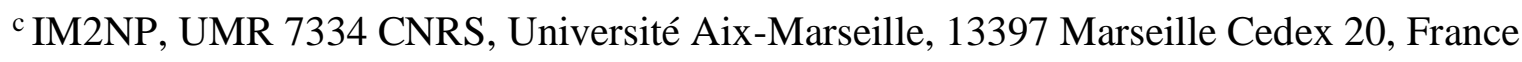 \\ *Corresponding author: xptan@ntu.edu.sg
}

\section{Abstract}

The nanometer-scale (nano-scale) microstructural evolution in an additively manufactured Refree Ni-based superalloy, with single crystal compositions, is investigated through field emission scanning electron microscopy, transmission electron microscopy, and atom probe tomography. We find that nano-scale primary $\gamma^{\prime}$ precipitation occurs in the fine as-built microstructure, leading to an exceptional microhardness of $480.0 \pm 6.7 \mathrm{HV}$ at room temperature. Presence of ultra-fine $\gamma^{\prime}$ precipitates, $\sim 20 \mathrm{~nm}$ in size, is observed in the bottom few layers of the as-built samples, which is hitherto undocumented and contrary to the widespread consensus regarding hierarchical $\gamma^{\prime}$ phase evolution in additively manufactured Ni-based superalloys. Moreover, considerable precipitation of tantalum-rich C14 Laves phase at the grain boundaries and interdendritic regions in the as-built samples emphasizes the need for additive manufacturing specific alloy design.

Keywords: additive manufacturing; electron beam melting; superalloy; nano-scale; precipitation

Metal additive manufacturing (AM) processes have shown great potential in the fabrication of complex metallic systems[1-3]. Among these, electron beam powder bed fusion (E-PBF) also kown as selective electron beam melting (SEBM) has been incredibly successful in producing Ni-based superalloy parts for high-temperature applications [4-7]. Moreover, the SEBM 
1 process inherently introduces ultrahigh unidirectional thermal gradients $\left(\sim 10^{6} \mathrm{~K} / \mathrm{m}\right)$ which assist in the strengthening of $<001>$ crystallographic texture with build height [8]. Due to these unique characteristics, SEBM has recently emerged as 'the metal AM process' for fabricating Ni-based superalloy single crystals (SXs) [5-7]. A favourable addition to the SEBM's capability of printing bulk SXs is the significantly reduced time for homogenisation heat treatment - due to the as-built dendritic microstructure that is orders of magnitude finer than their conventional counterparts $[6,9]$.

The current research on SEBM fabrication of Ni-based superalloy SXs is promising, given the comparable creep properties of SEBMed Ni-based SX superalloy - CMSX4, with that of its conventional counterpart [10]. While this raises hopes that SEBM can potentially replace conventional manufacturing methods in critical applications, some microstructural aspects need further scrutiny. For instance, hierarchical and heterogeneous distribution of $\gamma^{\prime}$ phase $[6,10]$ - an inherent property of layer-wise fabrication, has been identified to affect the creep properties of both - the as-built and heat-treated SEBM-built parts [10]. Moreover, Ni-based superalloys containing a high amount of refractory elements exhibit a strong tendency to form topologically close-packed (TCP) phases, such as $\mu, \sigma, \delta, \mathrm{P}, \mathrm{R}$, Laves phases when exposed to elevated temperatures [11-13]. Given the elemental segregation and the inherent annealing effect of SEBM process (e.g. build temperatures of $900-1100{ }^{\circ} \mathrm{C}$ ), it is likely that TCP phases, which are particularly detrimental to the creep properties of Ni-based superalloys $[11,14,15]$, may also precipitate in SEBM-built Ni-based SX superalloy parts - as observed in SEBMfabricated Inconel 718 [16]. However, to our bewilderment, precipitation of such phases during SEBM fabrication of Ni-based superalloys with SX compositions has hardly been acknowledged in the literature [17]. Since addressing these issues will lead to a better understanding of processing-microstructure-property relationships in them, we conducted a thorough nano-scale microstructural and compositional investigation of the $\gamma / \gamma^{\prime}$ and TCP phases in one such SEBM-built Ni-based superalloy with SX compositions.

The spherical pre-alloyed powder material (D50 diameter of $\sim 30 \mu \mathrm{m}$ ) of a Ni-based superalloy with first-generation SX Re-free compositions of $\mathrm{Ni}-5.5 \mathrm{Al}-7.4 \mathrm{Ta}-4.4 \mathrm{~W}-7.1 \mathrm{Co}-7.5 \mathrm{Cr}-1.2 \mathrm{Ti}-$ 2.0Mo (wt.\%) [18][19] was used to fabricate bulk samples $\left(30 \times 30 \times 5 \mathrm{~mm}^{3}\right)$ based on a conventional stainless steel substrate with the commercial Arcam A2XX SEBM system. An average build temperature of $\sim 1000{ }^{\circ} \mathrm{C}$ was employed for the fabrication, and the detailed process parameters for the fabrication process can be found elsewhere [19]. The design of experiment (DOE) approach was used to optimize the SEBM process parameters that can 
1 produce the samples with the highest relative density and flat top surfaces. Given its nonweldable nature, this alloy was prone to cracking during SEBM fabrication. It is noteworthy that the bulk samples used for this study were not completely crack-free, while remaining some minor intergranular cracks particularly at the upper sections. A detailed investigation of the cracking phenomenon and a cracking criterion that incrorporates the material properties, microstructural and solidification parameters has been presented in a separate article [19]. The as-built fine microstructure was examined using JEOL JMS-7600F field emission scanning electron microscope (FESEM). Compositional analyses of the specimens were performed using the Oxford Instruments' energy dispersive spectroscopy (EDS) equipped with the FESEM. Bulk phase analysis of the as-built specimens was investigated by $\mathrm{x}$-ray diffraction (XRD) using a PANalytical Empyrean system. JEOL's JEM-2010 transmission electron microscope (TEM) was employed for the nano-scale compositional analyses of the TCP phases. Atom probe tomography (APT) specimens prepared by the focused ion beam (FIB) technique from specific regions of interest (ROIs) were examined by the local-electrode atom probe (LEAP) $3000 \mathrm{X} \mathrm{HR}$ at $70 \mathrm{~K}$ and a gauge pressure $<2.0 \mathrm{e}^{-11}$ Torr under the voltage mode. Data analysis was performed using IVAS 3.8.2 software, and compositional analysis was carried out by using both the proximity histogram (proxigram) and one-dimensional (1D) concentration profile methods. Vickers micro-hardness (HV) tests were performed on the XY cross-sections of the as-built samples, perpendicular to the build direction, using the Future-Tech's FM-300e with a load of $300 \mathrm{~g}$ and dwell time of $15 \mathrm{~s}$. To extrapolate the microstructural observation results from the current small builds to that of large scale, we performed post aging heat treatment for the as-built bulk samples at $900{ }^{\circ} \mathrm{C}$ for 24 hours that can simulate the long-time, in-situ high-temperature SEBM process.

Figure 1 presents the FESEM observations and the bulk phase analysis of the as-built microstructure. Figure 1 (a) shows the back-scattered electron (BSE) image of the equiaxedto-columnar transition region taken along the longitudinal direction. The primarily equaixed microstructure in the bottom few layers of the SEBM-built parts results from the explosive nucleation due to a large degree of undercooling given the region's vicinity to the substrate plate [20-22]. As seen in Figure 1 (a) a large number of secondary phase precipitates (bright particles) are present in the equiaxed grain region close to the substrate plate. Moreover, visual inspection reveals a decreasing population density of these precipitates along the build direction. Figure 1 (b) and (c) show the XRD profiles obtained in the cross sections of columnar and equiaxed-to-columnar transition regions, respectively. The profile shown in Figure 1 (c) 
1 contains a few peaks (labelled with 'red cross') absent in Figure 1 (b) which likely correspond 2 to the secondary phase precipitates abundant in the equiaxed and equiaxed-to-columnar 3 transition regions. Figure 1 (d) displays the compositional analysis performed on the 4 longitudinal section from the columnar grain region with the primary dendrite arm spacing of $\sim 4 \mu \mathrm{m}$. The correlative EDS mapping (Figure 1 (e)) reveals many precipitates that were rich 6 in Ta, W, and Mo and limited to the grain boundaries (GBs) and interdendritic regions (also 7 known as sub-GBs). We note that all these precipitates are nano-scale particles.

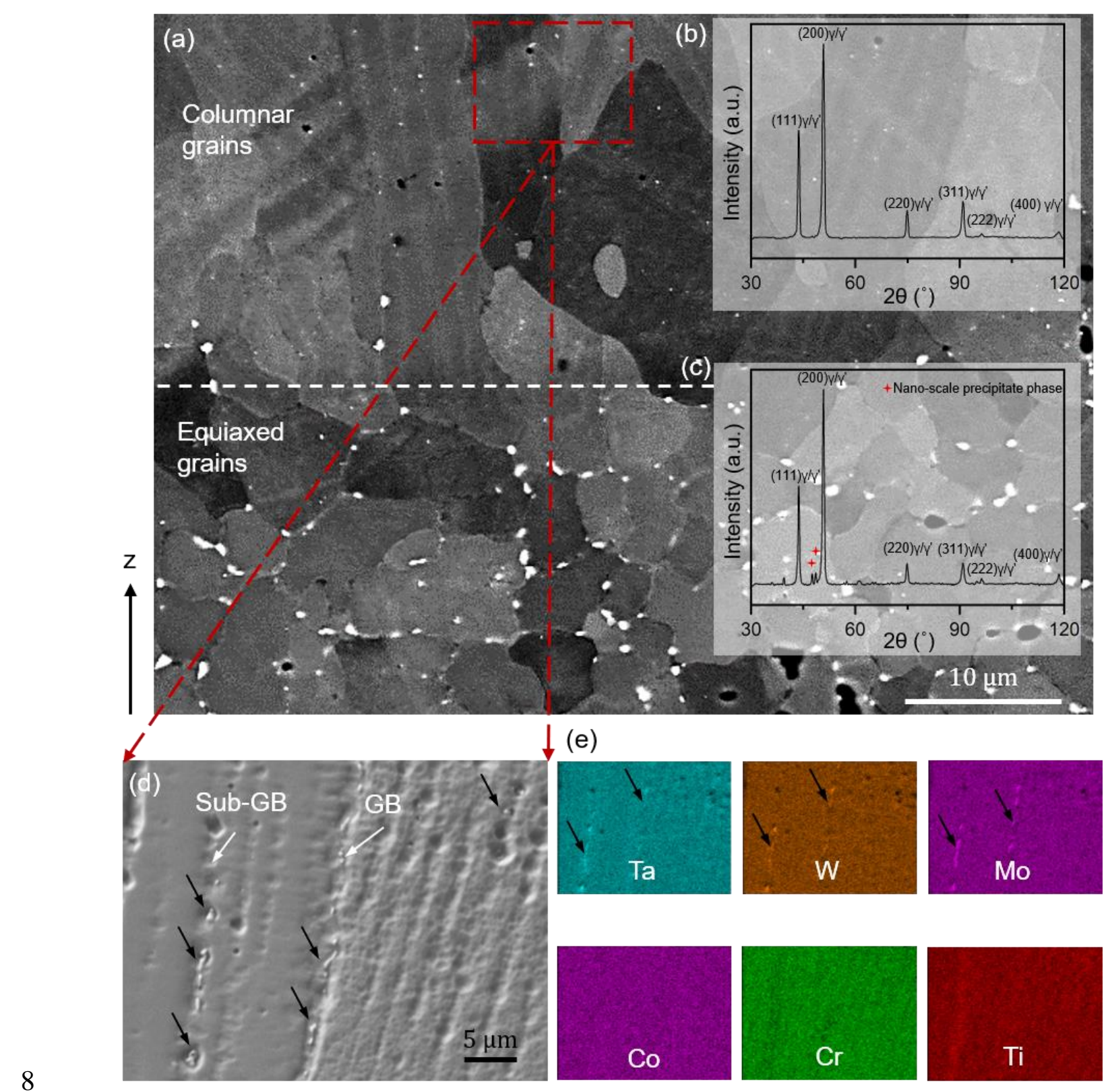

9 Figure 1 (a) Backscattered electron (BSE) micrograph of the longitudinal section of the equiaxed-to10 columnar transition region in SEBM-built superalloy sample. (b) XRD profile recorded in the columnar 11 grain region. (c) XRD profile in the equiaxed-to-columnar transition region. (d) SEM micrograph of an 
1 enlarged view of columnar grain region from (a) with precipitates at sub-GBs and GBs (Black arrows).

2 (e) The corresponding elemental maps show obvious enrichment of Ta, W and Mo in the precipitates.

3

4 The as-built microstructure was further analysed by TEM. Figure 2 shows the bright-field TEM 5 images of the GB precipitates, and the $\gamma / \gamma^{\prime}$ dual-phase microstructure with their corresponding 6 SAED patterns from the columnar region of the as-built samples. Majority of the secondary 7 precipitates are shown to be irregular in morphology and $200-400 \mathrm{~nm}$ in size. Figure 2 (a) 8 shows that the nano-scale precipitates labelled as 1, 2, and 3 cluster together. The 9 corresponding SAED pattern was indexed along the $[111]_{\gamma} / /[1 \overline{1} 01]_{\mathrm{C} 14}$ zone axis. Figure 2 (b) 10 is a magnified image of the precipitate 1 labelled in Figure 2 (a) with its corresponding SAED 11 pattern indexed along the $[211]_{\gamma} / /[11 \overline{2} 3]_{\mathrm{C} 14}$ zone axis. Likewise, Figure 2 (c) is a TEM bright12 field image of another $\sim 400 \mathrm{~nm}$-sized cuboidal precipitate with its corresponding SAED 13 pattern along the $[\overline{5} 504]_{\mathrm{C} 14}$ zone axis. Based on massive TEM observations, it can be inferred 14 that the secondary phase precipitated at columnar GBs is the C14 Laves phase with a hexagonal 15 close-packed (hcp) structure. 


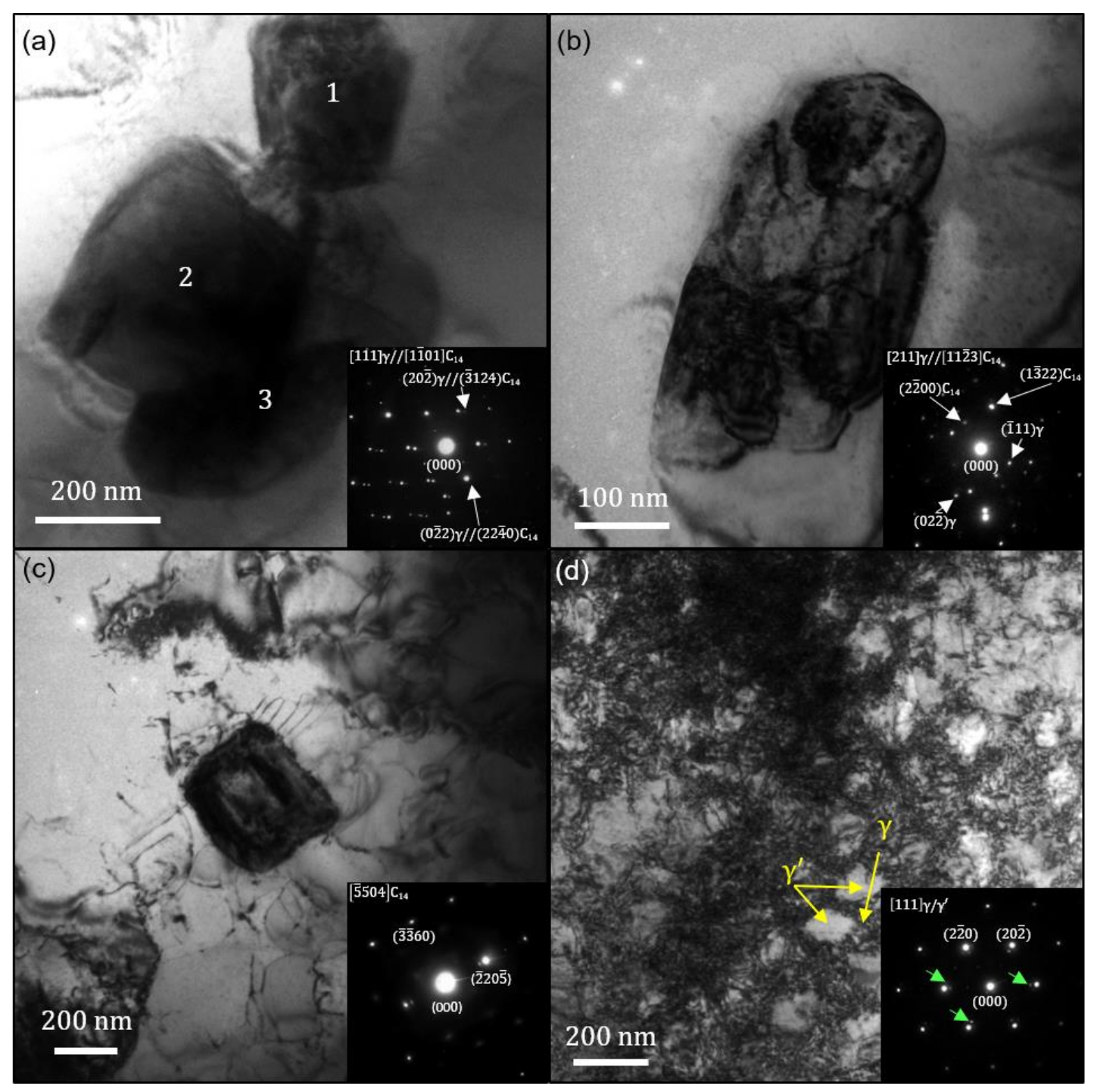

2 Figure 2 Bright-field TEM images showing the nano-scale microstructural features in as-built samples.

3 (a) Agglomeration of 3 irregular C14 Laves TCP phase precipitates observed along [111] $]_{\gamma}$ zone axis.

4 (b) A magnified view of precipitate 1 from (a) as seen along [211] $\gamma$ zone axis. (c) A cuboidal shaped

5 C14 Laves TCP phase precipitate as seen along $[\overline{5} 504]_{C 14}$ zone axis. (d) Bright-field TEM image

6 showing $\gamma^{\prime}$ precipitation through the spinodal decomposition as observed along [111] $]_{\gamma / \gamma^{\prime}}$ zone axis. The

7 corresponding SAED pattern shows satellite reflections associated with the spinodal decomposition.

9 In terms of the TEM-EDS analysis, we know that the precipitates are remarkably enriched in

$10 \mathrm{Ta}(\sim 50$ at.\%). Moreover, peaks belonging to the secondary phase precipitates shown in Figure

111 (c) - at $2 \theta(\mathrm{d})$ values of $48.07^{\circ}(1.892 \AA)$ and $49.05^{\circ}(1.857 \AA)$, correspond to that of (202)

12 and (104) planes for a C14 Laves phase with lattice parameters of $\mathrm{a}=0.4916 \mathrm{~nm}$ and $\mathrm{c}=0.8303$

$13 \mathrm{~nm}$. Moreover, the determined lattice parameters match well with the theoretically calculated

14 values of 0.4914 and 0.8004 , respectively, for the $\mathrm{C} 14 \mathrm{TaCr}_{2}$ Laves phase [23]. Hence, it is

15 suggested to be the $\mathrm{MgZn}_{2}$ prototype of C14 Laves phase with a stoichiometric formula of 
$1 \mathrm{TaCr} 2$. We understand that the presence of $\mathrm{C} 14$ Laves based TCP phase precipitates in our specimens is the outcome of the inherent nature of rapid solidification in AM. It facilitates the micro-segregation of heavy elements such as Ta, Mo, and W, which, in turn, favour the formation of Laves based TCP phase precipitates in the Ni-based superalloy considered in the present study [24]. A higher volume fraction of TCP phase precipitates are observed at the bottom of the build (Figure 1 (a)) as the region close to the substrate plate was exposed to higher temperatures for longer periods than that of the layers deposited over them. The process of reheating is also responsible for the formation of symmetric and regular shaped precipitates (see Figure 2 (c)) obeying solid phase transformation mechanisms.

The primary $\gamma^{\prime}$ precipitates were identified and labelled within the $\gamma$ matrix in Figure 2 (d). The corresponding SAED pattern of this image along the [111] $]_{\gamma / \gamma^{\prime}}$ zone axis is shown in the inset of Figure 2 (d). Presence of satellite reflections in the SAED pattern (green arrows) suggests that the precipitation of ordered $\gamma^{\prime}$ precipitates from supersaturated $\gamma$ solid solution [18] occurred via the spinodal decomposition mechanism [25-27]. These $\gamma^{\prime}$ precipitates are nearly spherical with an average size of $\sim 100 \mathrm{~nm}$.

To quantitatively analyse the composition of the nano-scale $\gamma / \gamma^{\prime}$ dual-phase microstructure, and that of the TCP phase precipitates observed in abundance in Figure 1, APT was utilised. Figure 3 (a) shows a FESEM micrograph with two ROIs - labelled 1 and 2, respectively. ROI-1 is located in the equiaxed-to-columnar transition region in the SEBM-built superalloy. ROI-2 is located below ROI-1, in the equiaxed zone at the bottom of the build. In the APT reconstructed volumes (RVs), only $\mathrm{Cr}$ and $\mathrm{Al}$ atoms are displayed as the indicators for varying phases. Figure 3 (b), (c), and (d) show the APT images of three RVs - termed RV-1, RV-2, and RV-3, respectively. It is evident from Figure 3 that RV-1 and -2 belong to the $\gamma / \gamma^{\prime}$ dual-phase microstructure. While RV-3, given the uniform distribution of $\mathrm{Cr}$ in the APT image, belongs to the region of a TCP phase precipitate. It is noted that, lots of $\sim 20 \mathrm{~nm}$-sized $\gamma^{\prime}$ precipitates were found embedded within the $\gamma$ matrix in RV-2, and RV-1 merely contains a larger $\gamma^{\prime}$ precipitate, $\sim 100 \mathrm{~nm}$ in size, surrounded by the $\gamma$ matrix. Two curved $\gamma / \gamma^{\prime}$ interfaces are observed on the top and bottom edge of RV-1, which indicates that the $\gamma^{\prime}$ precipitate has a nearspherical morphology. This observation is in good agreement with the TEM image shown in Figure 2 (d). 


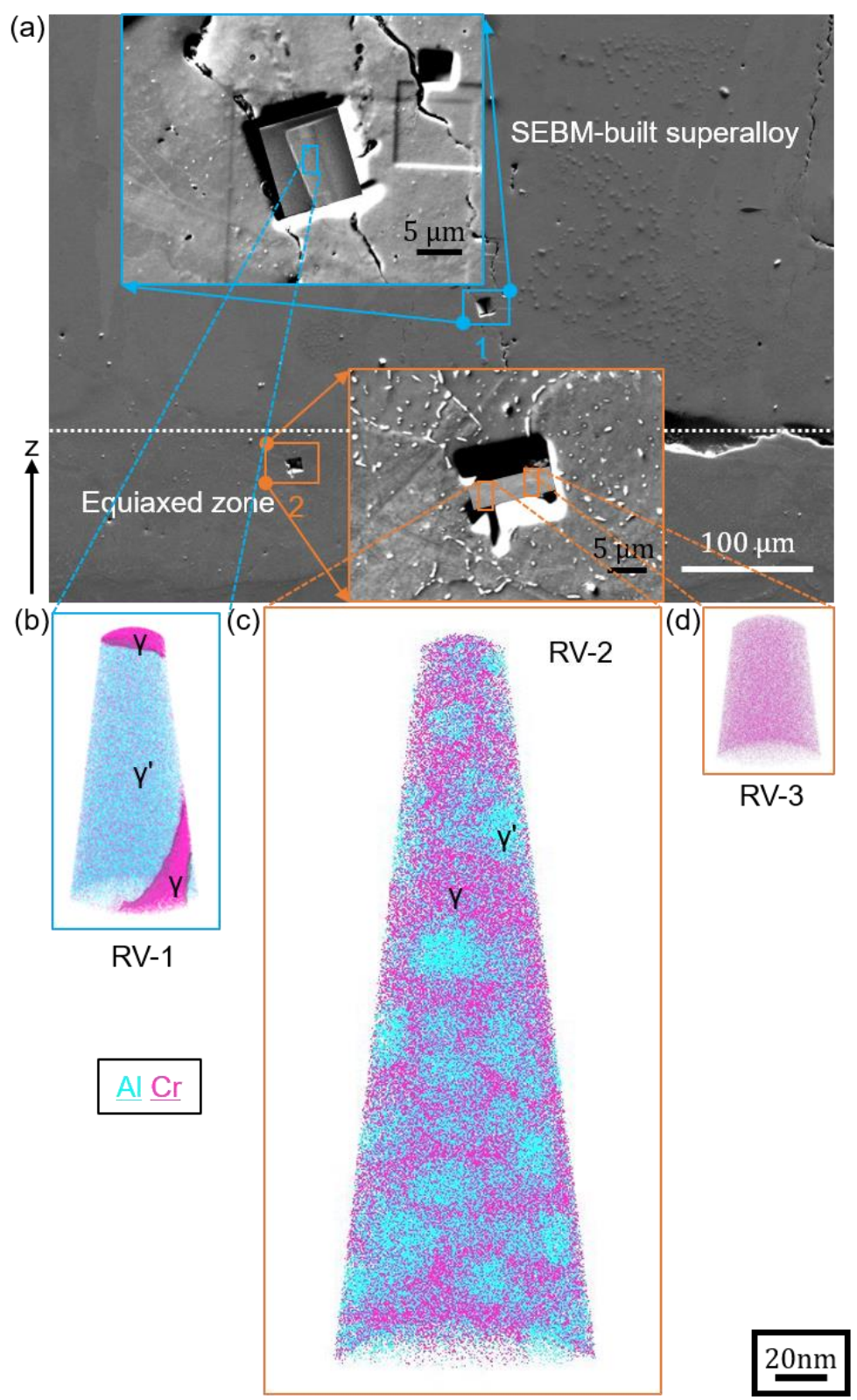

2 Figure 3 APT of SEBM-built Ni-based superalloy. (a) Micrograph indicating the two regions of interest 3 (ROIs) chosen for APT analyses. (b) APT reconstructed volume showing the $\gamma^{\prime}$ precipitation in the 4 equiaxed-to-columnar transition region in pure SEBM-built superalloy. (c) APT reconstructed volume 5 showing the $\gamma^{\prime}$ precipitation in the equiaxed zone (initially deposited layers). (d) APT reconstructed 6 volume of the bright intermetallic phase observed in abundance at the GBs in the equiaxed grain 7 microstructure. 

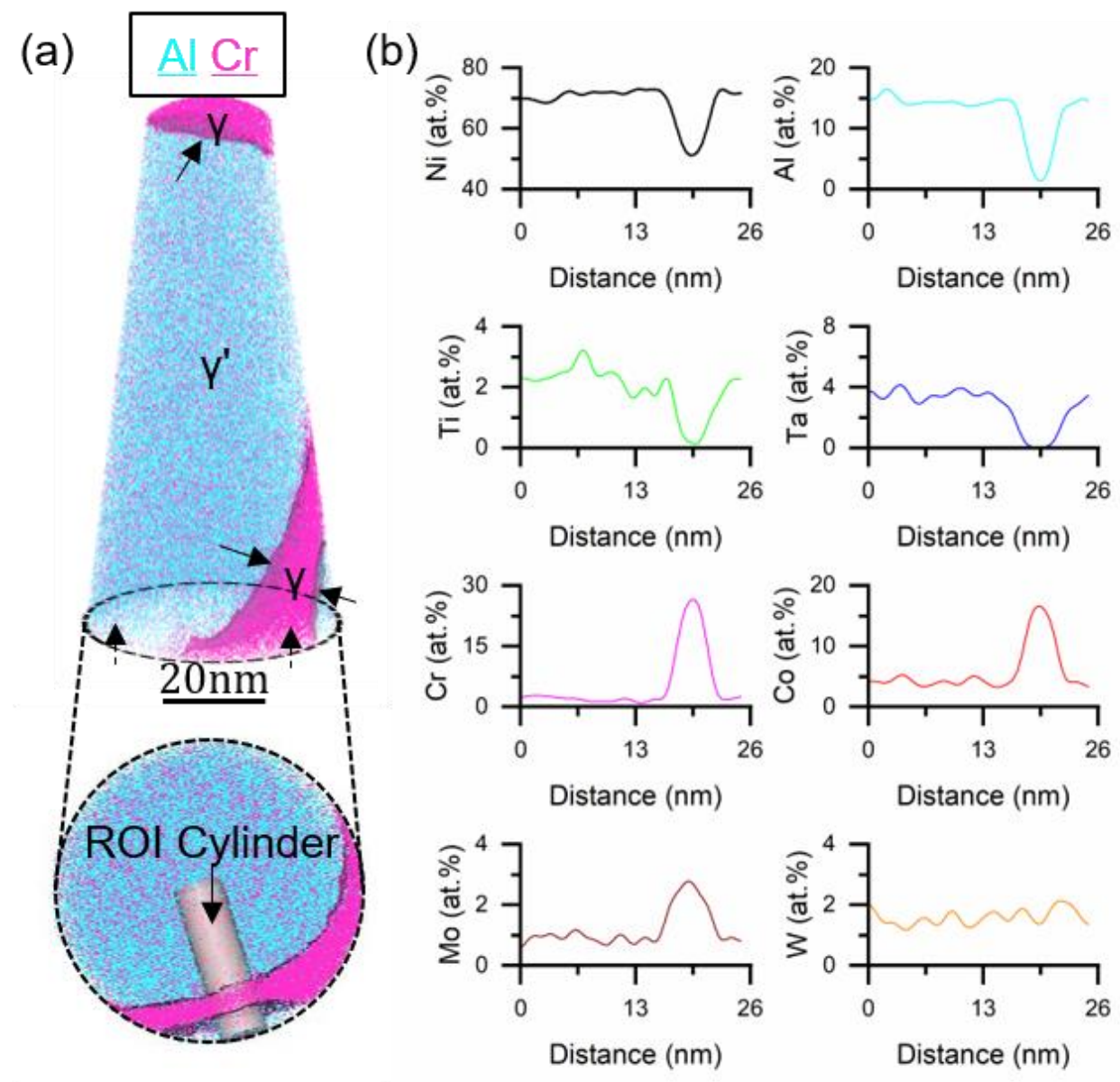

(c)

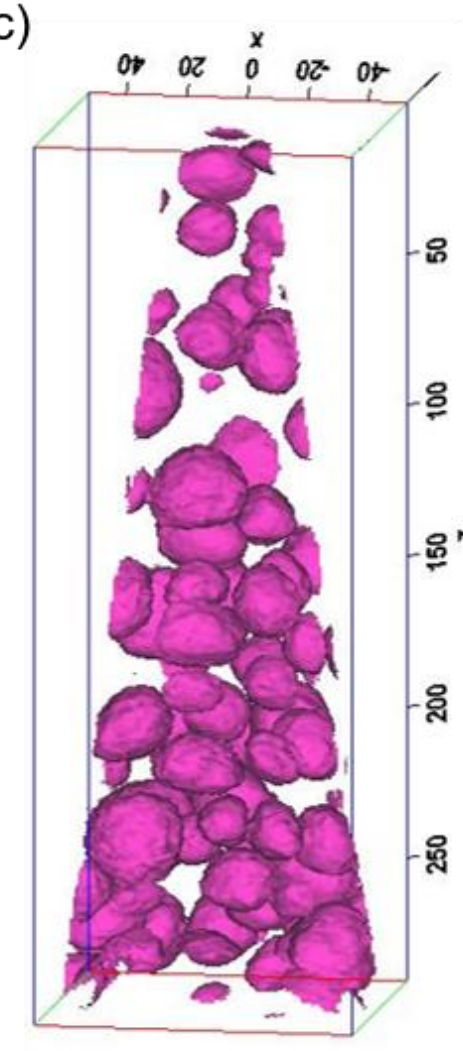

웅 (d)

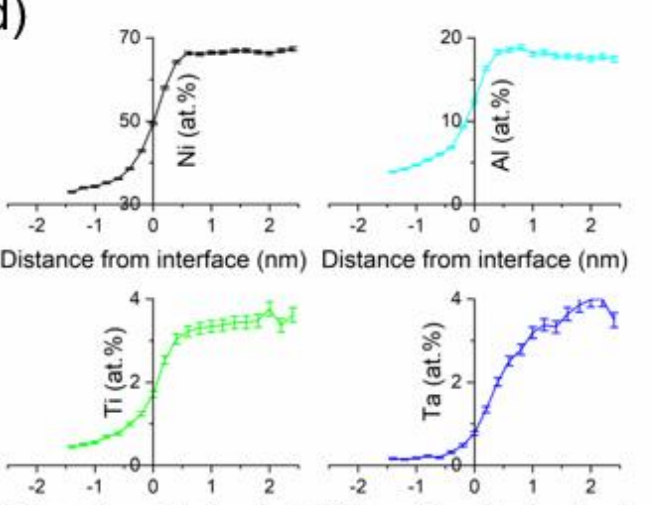

Distance from interface $(\mathrm{nm})$ Distance from interface $(\mathrm{nm})$

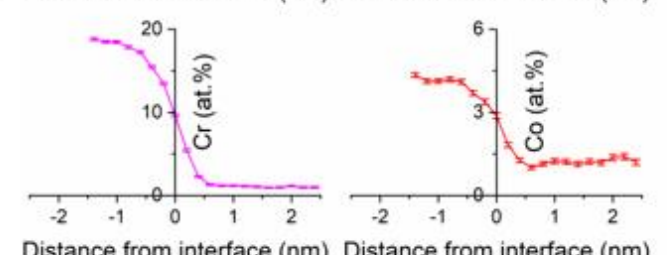

Distance from interface $(\mathrm{nm})$ Distance from interface $(\mathrm{nm})$

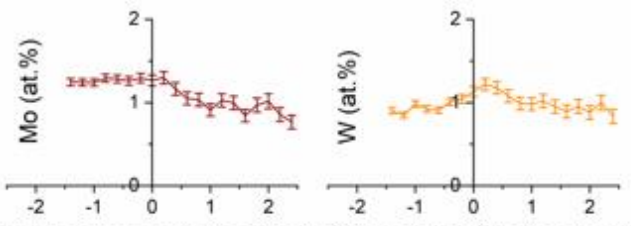

Distance from interface $(\mathrm{nm})$ Distance from interface $(\mathrm{nm})$ 
1 Figure 4 (a) RV-1 showing a $\gamma^{\prime}$ precipitate $\sim 100 \mathrm{~nm}$ in size with well-defined $\gamma / \gamma^{\prime}$ interfaces. (b) 1D 2 concentration profiles of the constituent elements across the ROI cylinder. (c) RV-2 showing spherical $3 \gamma^{\prime}$ precipitates $\sim 20 \mathrm{~nm}$ in size. (d) Proxigrams showing the concentration profiles of the constituent elements across the $\gamma^{\prime} / \gamma^{\prime}$ interface.

6 Figure 4 (a) and (c) display the APT images of RV-1 - with 15 at. \% $\mathrm{Cr}$ isoconcentration surfaces (isosurfaces), and RV-2 - with 10 at.\% Cr isosurfaces, respectively. Figure 4 (b) and (d) present the $1 \mathrm{D}$ concentration profiles plotted along the ROI cylinder of RV-1, and proxigrams for RV-2, respectively. It is evident from RV-1 and RV-2 that the microstructure is composed of nano-scale $\gamma^{\prime}$ embedded in the $\gamma$ matrix. It is noteworthy that, besides $\mathrm{W}$, the partitioning behaviours of the constituent elements in the $\gamma / \gamma^{\prime}$ phase is similar to that observed in the solution heat-treated counterpart that resembles the compositions [18]. $\mathrm{Ni}, \mathrm{Al}, \mathrm{Ti}$, and Ta partition strongly to the $\gamma^{\prime}$ phase, while $\mathrm{Cr}$, Mo, and Co act as $\gamma$ phase strengtheners. W, on the other hand, deviates from its natural behaviour of partitioning to the $\gamma$ phase in multicomponent alloys [28] and distributes uniformly across the two phases. Micro-hardness measurements in the XY-plane of as-built samples from the columnar region yield a hardness value of $480.0 \pm 6.7 \mathrm{HV}$ or $4.7 \pm 0.1 \mathrm{GPa}$, which is superior to $\sim 450 \mathrm{HV}$ reported in an earlier work of SEBM-built Ni-based SX superalloy - CMSX4 [5]. We believe that this improvement can be attributed to both the fine nano-scale microstructure and the strengthening of the $\gamma^{\prime}$ phase by $\mathrm{W}$ in our SEBM-built Ni-based superalloy samples.

Straight away, it is evident from Figure 4 that there is a pronounced difference between the $\gamma / \gamma^{\prime}$ dual-phase microstructure obtained in ROI-1 and -2. These observations conform to an earlier work where Tan et al. [18] determined that employing a high cooling rate ( $1273 \mathrm{~K} / \mathrm{s})$ during solution heat-treatment of Ni-based AM1 SX superalloy, from $1300{ }^{\circ} \mathrm{C}$, resulted in precipitation of 30 - $50 \mathrm{~nm}$-sized, spherical $\gamma^{\prime}$ precipitates with diffuse $\gamma / \gamma^{\prime}$ interfaces. On the contrary, solutionised alloy subjected to a lower cooling rate $(\sim 274.25 \mathrm{~K} / \mathrm{s})$ contained $70-100$ nm-sized $\gamma^{\prime}$ precipitates with well-defined $\gamma / \gamma^{\prime}$ interfaces. These inferences can be applied to understand the differences in precipitation behaviour observed in RV-1 and RV-2 as the thermal history of deposited layers in AM closely resemble that of a solution heat-treated superalloy. Since the $\gamma^{\prime}$ precipitates in RV-2 are much smaller than that in RV-1, it can be asserted that ROI-2 was subjected to a higher cooling rate (> $1273 \mathrm{~K} / \mathrm{s})$ than ROI-1 during the SEBM process. Even though the bottom layers of a SEBM-built part are subjected to longer 
1 reheating times due to remelting of consecutive layers, the initially deposited layers of the build 2 (ROI-2) is different since it is the fusion zone between stainless steel substrate plate and 3 deposited superalloy. The large volume of the substrate plate causes better dissipation of heat

4 from the first layer in comparison to the consecutive layers. Hence, a higher cooling rate in the 5 equiaxed region during solidification and post-heating leads to the formation of $\sim 20 \mathrm{~nm}$-sized $6 \gamma^{\prime}$ precipitates observed in Figure 4 (c). This observation is unique to our work, and it 7 contradicts the general trend of $\gamma^{\prime}$ phase evolution as reported in earlier works $[5,6]$ where a

8 linear reduction in the $\gamma^{\prime}$ precipitate sizes were observed with build height.

9 We suspect that a higher cooling rate in ROI-2 is also the reason behind severe TCP phase 10 precipitation in the region as seen in RV-3. As seen in Table 1, the partitioning behaviours of 11 the constituent elements of the SEBM-built Ni-based AM1 superalloy in the $\gamma / \gamma^{\prime}$ dual-phase microstructure obtained for RV-1 resembles closely to that of a heat-treated as-cast AM1 superalloy for LC [18]. The deviation in the partitioning of $\mathrm{W}$ is evident as its partitioning ratio $K_{\gamma^{\prime} / \gamma}$ comes out to be $\sim 1.2$, providing an evidence of the departure from equilibrium solidification [29]. The same for solution heat-treated as cast AM1 superalloy can be determined from Table as $~ 0.6$ under LC post-homogenisation [18]. The abnormal partitioning behaviour of $\mathrm{W}$ may be of particular interest to further understand the nano-scale $\gamma^{\prime}$ precipitation and its effects on mechanical properties, which will be left for detailed investigations in the future.

Table 1 Chemical compositions (at.\%) of the $\gamma / \gamma^{\prime}$ dual-phase microstructure measured by APT in the SEBM-built superalloy (RV-1) along with its comparison with the chemical composition 23 of the $\gamma / \gamma^{\prime}$ dual-phase microstructure observed in solutionised AM1 superalloy subjected to low 24 cooling (LC) post-homogenisation [18].

\begin{tabular}{|c|c|c|c|c|c|c|c|c|c|}
\hline & & $\mathbf{N i}$ & $\mathrm{Cr}$ & Co & Mo & $\mathbf{W}$ & $\mathbf{T i}$ & Al & $\mathbf{T a}$ \\
\hline Powde & & 65.63 & 8.55 & 7.15 & 1.22 & 1.41 & 1.48 & 12.15 & 2.41 \\
\hline \multirow[t]{2}{*}{ RV-1 } & $\gamma$ & $51.25 \pm 0.26$ & $26.54 \pm 0.23$ & $16.52 \pm 0.19$ & $2.69 \pm 0.06$ & $1.38 \pm 0.07$ & $0.14 \pm 0.03$ & $1.4 \pm 0.08$ & $0.06 \pm 0.03$ \\
\hline & $\gamma^{\prime}$ & $69.82 \pm 0.35$ & $2.64 \pm 0.10$ & $4.14 \pm 0.18$ & $0.87 \pm 0.05$ & $1.73 \pm 0.10$ & $2.25 \pm 0.10$ & $15.06 \pm 0.28$ & $3.28 \pm 0.13$ \\
\hline $\mathbf{L C}$ & $\gamma$ & $50.86 \pm 0.55$ & $26.84 \pm 0.69$ & $14.91 \pm 0.20$ & $2.94 \pm 0.19$ & $1.69 \pm 0.11$ & $0.07 \pm 0.02$ & $2.23 \pm 0.02$ & $0.46 \pm 0.01$ \\
\hline [18] & $\gamma^{\prime}$ & $70.37 \pm 0.10$ & $1.89 \pm 0.07$ & $3.97 \pm 0.07$ & $0.74 \pm 0.01$ & $1.04 \pm 0.05$ & $1.89 \pm 0.04$ & $16.18 \pm 0.07$ & $3.92 \pm 0.07$ \\
\hline
\end{tabular}


1 The compositional analysis of RV-3, reveals that it is rich in Ta (13.99 at.\%), Mo (9.73 at.\%) and $\mathrm{W}(6.28$ at.\%). This confirms the hypothesis made from Figure 1 that the segregation of these 3 heavy elements during solidification, and the subsequent reheating, indeed results in the formation of Ta-rich C14 Laves based TCP phase precipitates in our SEBM-built Ni-based superalloy samples.

6 We understand that it is a typical first-generation, thermally stable Ni-based SX superalloy under the directional solidification and even long-term aging conditions. However, it is found that the massive precipitation of nano-scale $\gamma^{\prime}$ and TCP phases in microstructure is a universial phenomenon for this Ni-based superalloy regardless of the varying process parameters applied in the previous trial-and-error fabrications. Furthermore, the post heat treatment results (see Supplementary Material) show that the nano-scale precipitation phenomenon is still dominant and the nano-sized $\gamma^{\prime}$ precipitates in the as-built sample are thermally stable. More importantly, there was a significant increase in the TCP precipitates in the regions that were primarily TCPfree in the as-built conditions. Therefore, the alloy redesign for additive manufacturing is necessary for fabricating high-performance, TCP-free superalloy SXs.

Overall, we determined that the microstructure of a SEBM-built Ni-based superalloy with firstgeneration SX Re-free compositions consists of nano-scale primary $\gamma^{\prime}$ phase embedded in the $\gamma$ matrix. Along with it, numerous precipitation of TCP C14 Laves phases, $\sim 200-400 \mathrm{~nm}$ in size, occurred both at GBs and interdendritic regions. Even though the rapid solidification associated with the SEBM process did not affect the partitioning behaviours of the constituent elements with the exception of $\mathrm{W}$, the enrichment of GBs with heavy elements such as Ta, Mo and $\mathrm{W}$ drives the TCP phase precipitation under the influence of the in-situ annealing effect of SEBM. Observation of ultra-fine $\gamma^{\prime}$ precipitates in the bottom equiaxed zone, $\sim 20 \mathrm{~nm}$ in size, shows a promise of achieving a superior nano-scale microstructure through SEBM process. The uniform partitioning of $\mathrm{W}$ across the $\gamma / \gamma^{\prime}$ phase in the nano-scale microstructure of multicomponent Ni-based superalloy is unique to this work and requires further investigations to quantify its effect on the high-temperature mechanical properties of the SEBM-built parts.

\section{Acknowledgements}

This work was supported by the Medium-Sized Centre funding scheme awarded by the National Research Foundation, Prime Minister's Office, Singapore. The authors are grateful to financial support from the French METSA network (FR3507) for APT experiments. 


\section{References}

[1] W.J. Sames, F.A. List, S. Pannala, R.R. Dehoff, S.S. Babu, Int. Mater. Rev. 61 (2016) 315360 .

[2] T. DebRoy, H.L. Wei, J.S. Zuback, T. Mukherjee, J.W. Elmer, J.O. Milewski, A.M. Beese, A. Wilson-Heid, A. De, W. Zhang, Prog. Mater. Sci. 92 (2018) 112-224.

[3] S.S. Babu, N. Raghavan, J. Raplee, S.J. Foster, C. Frederick, M. Haines, R. Dinwiddie, M.K. Kirka, A. Plotkowski, Y. Lee, R.R. Dehoff, Metall. Mater. Trans. A 49 (2018) 3764-3780.

[4] C. Körner, Int. Mater. Rev. 61 (2016) 361-377.

[5] M. Ramsperger, C. Körner, in: Superalloys 2016 Proc. 13th Int. Symp. Superalloys, 2016, pp. 981-990.

[6] M. Ramsperger, R.F. Singer, C. Körner, Metall. Mater. Trans. A Phys. Metall. Mater. Sci. 47 (2016) 1469-1480.

[7] E. Chauvet, P. Kontis, E.A. Jägle, B. Gault, D. Raabe, C. Tassin, J.-J.J. Blandin, R. Dendievel, B. Vayre, S. Abed, G. Martin, Acta Mater. 142 (2018) 82-94.

[8] X.P. Tan, S. Chandra, Y. Kok, S.B. Tor, G. Seet, N.H. Loh, E. Liu, Materialia 7 (2019) 100365.

[9] M. Ramsperger, L.L. Mújica Roncery, I. Lopez-Galilea, R.F. Singer, W. Theisen, C. Körner, Adv. Eng. Mater. 17 (2015) 1486-1493.

[10] D. Bürger, A.B. Parsa, M. Ramsperger, C. Körner, G. Eggeler, Mater. Sci. Eng. A 762 (2019) 138098.

[11] C.M.F. Rae, R.C. Reed, Acta Mater. 49 (2001) 4113-4125.

[12] X.P. Tan, J.L. Liu, T. Jin, Z.Q. Hu, H.U. Hong, B.G. Choi, I.S. Kim, C.Y. Jo, Philos. Mag. Lett. 92 (2012) 556-562.

[13] S. Gao, Z.-Q. Liu, C.-F. Li, Y. Zhou, T. Jin, Acta Mater. 110 (2016) 268-275.

[14] J. Belan, Mater. Today Proc. 3 (2016) 936-941.

[15] A.S. Wilson, Mater. Sci. Technol. 33 (2017) 1108-1118.

[16] D. Deng, R.L. Peng, H. Söderberg, J. Moverare, Mater. Des. 160 (2018) 251-261.

[17] B. Ruttert, M. Ramsperger, L. Mujica Roncery, I. Lopez-Galilea, C. Körner, W. Theisen, Mater. Des. 110 (2016) 720-727.

[18] X.P. Tan, D. Mangelinck, C. Perrin-Pellegrino, L. Rougier, C.-A. Gandin, A. Jacot, D. Ponsen, V. Jaquet, Metall. Mater. Trans. A 45 (2014) 4725-4730.

[19] S. Chandra, X. Tan, R.L. Narayan, C. Wang, S.B. Tor, G. Seet, Addit. Manuf. (2020) 101633.

[20] S. Seetharaman, Fundamentals of Metallurgy, Elsevier, 2005.

[21] X. Tan, Y. Kok, Y.J. Tan, M. Descoins, D. Mangelinck, S.B. Tor, K.F. Leong, C.K. Chua, Acta Mater. 97 (2015) 1-16.

[22] J. Yang, Y. Chen, Y. Huang, Z. Ning, B. Liu, C. Guo, J. Sun, J. Mater. Sci. Technol. 42 (2020) $1-9$.

[23] X. Nie, Y. Du, H. Xu, Phys. B Condens. Matter 405 (2010) 4279-4282.

[24] C. Radhakrishna, K. Prasad Rao, J. Mater. Sci. 32 (1997) 1977-1984.

[25] J.W. Cahn, Acta Metall. 9 (1961) 795-801.

[26] E.P. Butler, G. Thomas, Acta Metall. 18 (1970) 347-365. 
1 [27] Y. Zhang, Z. Chen, D. Cao, J. Zhang, P. Zhang, Q. Tao, X. Yang, J. Mater. Res. Technol. 8 $2 \quad$ (2019) 726-736.

3 [28] Y. Amouyal, Z. Mao, D.N. Seidman, Acta Mater. 58 (2010) 5898-5911.

4 [29] D.M. Stefanescu, in: Sci. Eng. Cast. Solidif., Springer US, Boston, MA, 2002, pp. 4-19. 